DOI 10.37882/2223-2974.2020.10.20

\title{
ПОТЕНЦИАЛ СНИЖЕНИЯ СТАВОК ПО ИПОТЕКЕ К КОНЦУ 2020 ГОДА
}

\section{POTENTIAL FOR LOWER MORTGAGE RATES BY THE END OF 2020}

\section{E. Metreveli}

Summary: The purpose of this article is to explore the potential for lower mortgage rates by the end of 2020 .

The object of research is mortgage lending.

The subject of the study is the factors that influence the value of mortgage interest rates, as well as the forecast of their changes in 2020.

The following methods were used to conduct the study:

- statistical analysis (calculation of the dynamics of changes in mortgage rates for 2017-2020);

- correlation analysis of the relationship between mortgage rates, key rate, inflation rate, and return on assets;

- multiple regression analysis between mortgage rates, key rate, inflation rate, and return on assets.

Data from the Central Bank and the Federal state statistics service (Rosstat) served as the information base for the study.

The article analyzes the dynamics of mortgage lending rates for 20172019 , and forecasts changes in rates for the end of 2020. It is shown that the reduction of the key rate of the Bank of Russia at the end of 2020 to $3.5 \%$ and the inflation rate not higher than $4 \%$, in accordance with the constructed model of multiple regression, the mortgage rate can be $6.67 \%$.

Keywords: mortgage, mortgage lending, interest rates, commercial banks, housing, construction industry, analysis, forecast.
Метревели Елизавета Георгиевна

Аспирант, преподаватель, Российский экономический университет им. Г.В. Плеханова metrevelieg@yandex.ru

Аннотация: Целью данной статьи является исследование потенциала снижения ставок по ипотеке к концу 2020 года.

Объектом исследования является ипотечное кредитование.

Предметом исследования являются факторы, оказывающие влияние на величину процентных ипотечных ставок, а также прогноз их изменения в 2020 году.

Для проведения исследования была использованы следующие методы:

- статистический анализ (расчет динамики изменения ставок по ипотеке за 2017-2020 гг.);

- корреляционный анализ взаимосвязи между ставками по ипотеке, ключевой ставкой, уровнем инфляции, а также рентабельностью активов;

- множественный регрессионный анализ между ставками по ипотеке, ключевой ставкой, уровнем инфляции, а также рентабельностью активов.

Информационной базой исследования послужили данные Центрального Банка и Федеральной службы государственной статистики (Росстата).

В статье проведен анализ динамики ставок по ипотечному кредитованию за 2017-2019 гг., сделан прогноз изменения ставок на конец 2020 года. Показано, что снижение ключевой ставки Банка России на конец 2020 года до 3,5\% и уровне инфляции не выше 4\%, в соответствии с построенной модели множественной регрессии, величина ставки по ипотеке может составить 6,67\%.

Ключевые слова: ипотека, ипотечное кредитование, процентные ставки, коммерческие банки, жилье, строительная отрасль, анализ, прогноз.

доступность ипотечного кредитования приобретает в условиях кризиса, наблюдаемого в настоящее время, связанного как со снижением мировых цен на нефть, так и последствиями воздействия коронавирусной инфекции, как на мировую, так и на отечественную экономику.

В статье Ю.С. Караваевой проведен факторный анализ ипотечного рынка, ставок ипотечного кредитования, определены условия и процентные ставки ипотеки в 2017 году в крупнейших банках. Авторами данной статьи определены основные факторы регрессивного развития ипотечного рынка, к которым отнесены снижение курса рубля по отношению к курсу мировых валют, сокращение реальных располагаемых доходов населения, высокий уровень инфляции. По результатам исследования авторы утверждают, что желаемая ставка по ипотечному кредитованию находилась в 2017 году на уровне 7 \%, тогда как настоящая средневзвешенная - более 12 \% [8]. 
Несмотря на обширный анализ состояния ипотечного кредитования, в литературе не приводится прогноз по его развитию, в том числе, по потенциалу снижения ставок по ипотеке. Это также подтверждает актуальность выбранной темы.

Для проведения исследования была использованы следующие методы:

- статистический анализ (расчет динамики изменения ставок по ипотеке за 2017-2020 гг.);

- корреляционный анализ взаимосвязи между ставками по ипотеке, ключевой ставкой, уровнем инфляции, а также рентабельностью активов;

- множественный регрессионный анализ между ставками по ипотеке, ключевой ставкой, уровнем инфляции, а также рентабельностью активов.

Для оценки взаимосвязи был рассчитан коэффициент корреляции по следующей формуле:

$$
r_{x y}=\frac{\sum_{i=1}^{n}\left(x_{i}-\bar{x}\right)\left(y_{i}-\bar{y}\right)}{n \cdot \sigma_{x} \sigma_{y}}
$$

где $\mathrm{n}$ - объем исследуемой совокупности (объем выборки); $\bar{x}, \bar{y}$ - средние значения, $\sigma_{x}{ }^{2}, \sigma_{y}{ }^{2}$ - дисперсии, $\sigma_{x}, \sigma_{y}$ - среднеквадратические (стандартные) отклонения признаков у и х [7].

Информационной базой исследования послужили данные Центрального Банка и Федеральной службы государственной статистики (Росстата) [22].

В Российской Федерации высокие процентные ставки являются одной из основных проблем развития ипотечного кредитования. В то же время, нельзя не отметить их снижение в последние годы до 9 \% (а по государственной программе до 6,5\%), в то время как европейская ипотека начинается с 3\% в год. При этом, минимальный первоначальный взнос составляет не менее 10-20\% от суммы кредита, что не позволяет гражданам, нуждающимся в жилье, брать ипотечный кредит.

На величину процентной ставки влияют следующие факторы:

- ключевая ставка Центрального Банка (коммерческие банки привлекают средства от Центрального Банка под определенный процент);

- операционные расходы (стоимость содержания банка, зарплаты работников, связь, и другие);

- уровень инфляции;

- риск невозврата средств заемщиком (финансовое учреждение закладывает в стоимость кредита компенсацию за риск);

- риск, связанный с отдаленным будущим (долгосрочные кредиты более рисковые через неопределенность будущего);
- желаемый уровень прибыльности деятельности (целью деятельности коммерческого банка является получение прибыли).

При этом фактор девальвации отечественной валюты можно не принимать во внимание, так как в России ипотека выдается, преимущественно, в рублях.

Ставки по ипотеке в РФ за период с июня 2017 г. до июля 2020 г. имели тенденцию к снижению и сократились с 11,1\% до 8,74\%, динамика изменения составила $-2,36 \%$ (рис. 1).

При этом средневзвешенная ставка по ипотеке в новостройках в 15 крупнейших российских банках в июле 2020 года составляла 8,16\%, по ипотеке с государственной поддержкой $-6,17 \%$, по семейной ипотеке $-4,85 \%$, по ипотеке на вторичном рынке $-8,41 \%$, а по ипотеке с использованием рефинансирования - 8,18\% [17].

Прогноз ипотечной ставки по методу экспоненциального сглаживания на конец 2020 года, как видно, из рис. 1 , составляет $8,1 \%$.

Учитывая, что ставка по ипотечному кредитованию складывается из ключевой ставки, величины риска, уровня инфляции и ставки прибыльности (рентабельности) коммерческого банка, рассмотрим динамику данных составляющих, за исключением риска (так как это значение отсутствует в открытом доступе).

На рис. 2 представлена динамика изменения ключевой ставки, уровня инфляции и рентабельности активов коммерческих активов за 2017-2020 гг. Из рис. 2 видно, что динамика изменения ключевой ставки и показателя рентабельности активов в 2017-2019 гг. разнонаправленная - ключевая ставка за период снизилась с 9,25\% до 4,5\%, а рентабельности активов банковского сектора, напротив, выросла с 0,8\% до 1,9\%. При этом уровень инфляции находился примерно на одном уровне, и имел максимальные значения в декабре-январе 2018 г., апреле 2020 г., и минимальные значения и августе 2017 г., в августе 2018 г., в августе 2019 г.

Коэффициент корреляции между ставками по ипотеке и ключевой ставок составляет 0,876, следовательно, связь между этими показателями сильная и прямая. Коэффициент корреляции между ставками по ипотеке и показателем рентабельности активов коммерческих банков составляет -0,303, следовательно, связь между этими показателями обратная и умеренная. Между ставками по ипотеке и уровнем инфляции коэффициент корреляции составляет -0,235, следовательно, зависимость между данными показателями также является обратной и слабой (по шкале Чеддока) [7]. 


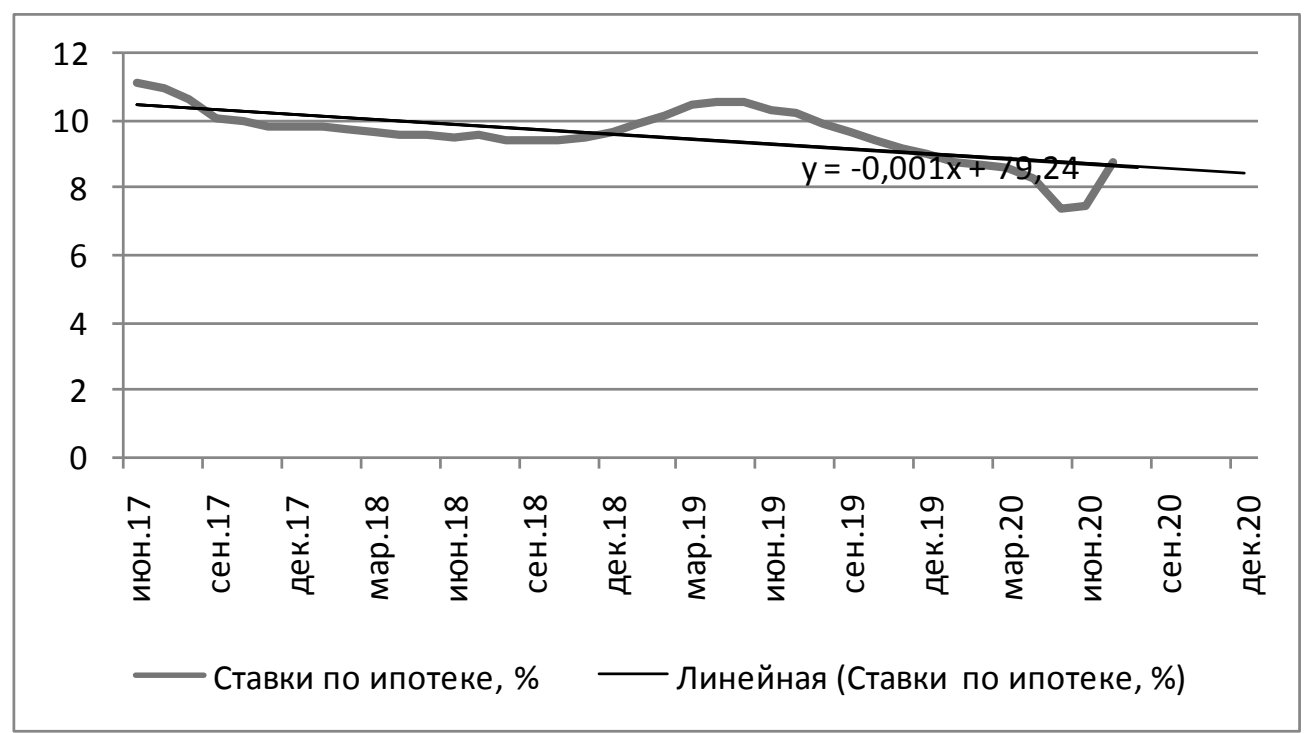

Рис. 1. Динамика изменения ставок по ипотеке за 2017-2020 гг. [21]

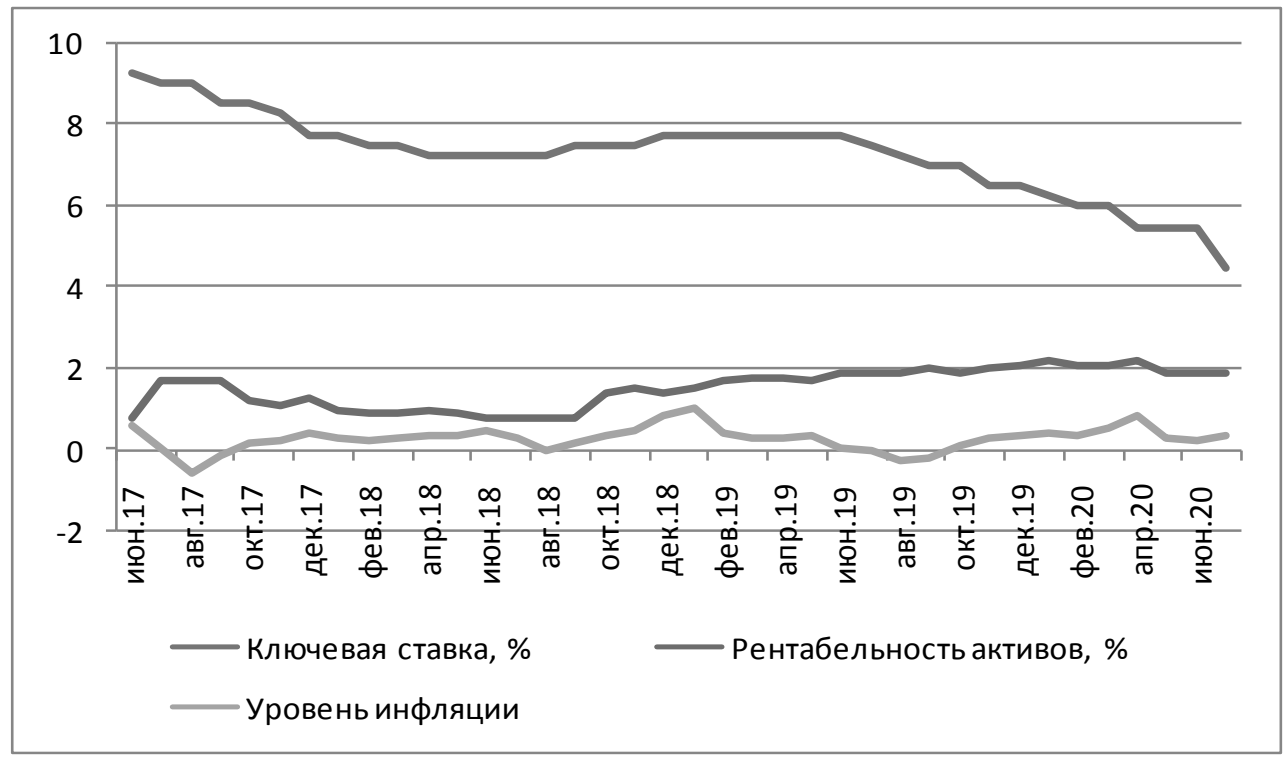

Рис. 2. Динамика изменения ключевой ставки, уровнем инфляции и рентабельности активов коммерческих активов за 2017-2020 гг. [17].

Матрица парных коэффициентов корреляции R представлена в табл. 1.

Таблица 1.

Матрица парных коэффициентов корреляции $\mathrm{R}$

\begin{tabular}{|c|c|c|c|c|}
\hline- & $y$ & $x_{1}$ & $x_{2}$ & $x_{3}$ \\
\hline$y$ & 1 & 0,8758 & $-0,3036$ & $-0,2229$ \\
\hline$x_{1}$ & 0,8758 & 1 & $-0,4626$ & $-0,2352$ \\
\hline$x_{2}$ & $-0,3036$ & $-0,4626$ & 1 & $-0,08716$ \\
\hline$x_{3}$ & $-0,2229$ & $-0,2352$ & $-0,08716$ & 1 \\
\hline
\end{tabular}

Уравнение множественной регрессии может быть представлено следующим образом:

$$
Y=3,8599+0,738 X_{1}+0,223 X_{2}+0,02594 X_{3} \text { ， }
$$

Где $\mathrm{Y}$ - процентные ставки по ипотеке;

$\mathrm{X}_{1}$ - ключевая ставка, \%;

$\mathrm{X}_{2}$ - рентабельности активов в банковской системе;

$\mathrm{X}_{3}$ - уровень инфляции, \%

Согласно закону «Об ипотеке», государственная программа рассчитана на период с 1 января 2018 по 31 декабря 2022 года. В бюджете 600 млрд руб. на поддержку граждан. Государственная поддержка направлена на повышение рождаемости в стране. Только те семьи, ко- 
торые планируют иметь второго или третьего ребенка в период с 01.01.2018 по 31.12.2022 могут претендовать на получение пособий. После окончания программы льгот процентная ставка по ипотеке вернется на уровень ключевой ставки Центрального банка + 2\% [1].

На основе экспертных данных выбранных факторных признаков, представим прогноз уровня процентных ставок по ипотеке на конец 2020 г.

По прогнозу Bank of America, Банк России на фоне пандемии может пойти на снижение ключевой ставки до $3,5 \%$ к концу года, если инфляция будет ниже цели $4 \%$ [24].

По прогнозу Банка России, инфляция по итогам 2020 г. будет находиться в интервале 3,7 - 4,2\%. Принимаем уровень инфляции по итогам 2020 г. в размере 4,0\%. Учитывая, что фактический уровень инфляции за первые 7 месяцев 2020 г. составил 2,95\%, среднемесячный уровень инфляции до конца 2020 г. составит: 0,21\% [19].

По мнению аналитиков агентства S\&P размер «плохих» долгов физических лиц существенно вырастет по итогам 2020 года вследствие ухудшения уровня общеэкономического развития, пандемии коронавируса и снижение цен на нефть. При этом, прибыль банков упадет не менее чем в два раза. В связи с этим, предполагаем снижение рентабельности активов до $1 \%$ к концу 2020 г. [20].

Зная значения факторных признаков (X1, X2, X3), можно представить прогноз результативного признака (Y) на конец 2020 года на основе найденного уравнения множественной регрессии:

$$
Y=3,8599+0,738 * 3,5+0,223 * 1+0,02594 * 0,21=6,67 \%
$$

Таким образом, на конец 2020 года величина ставки по ипотеке может составить 6,67\%. Это выше уровня прогноза, полученного по методу экспоненциального сглаживания.

В статье показано, что на уровень процентной ставки по ипотеке оказывают влияние ключевая ставка, уровень рентабельности активов в банковской системе и уровень инфляции. При этом между показателем ставки по ипотеке и ключевой ставкой зависимость сильная и прямая, между показателями ставки по ипотеке и уровнем рентабельности активов - обратная и умеренная, а также между ставкой по ипотеке и уровнем инфляции обратная и слабая.

Снижение инфляции позволит Центральному банку продолжить снижение ключевой ставки. Это, в свою очередь, повлечет снижение и процентной ставки по ипотечному кредитованию. Согласно построенной модели множественной регрессии, на конец 2020 года величина ставки по ипотеке может составить 6,67\%. При этом уровень ключевой ставки должен составлять 3,5\%, уровень инфляции по итогам 2020 года - не выше 4\%, а уровень рентабельности активов по банковской системе в целом принят в размере $1 \%$.

\section{ЛИТЕРАТУРА}

1. Федеральный закон «06 ипотеке (залоге недвижимости)» от 16.07.1998 № 102-Ф3 (в ред. 21.08.2020)

2. Буранбаева Л.3., Сабирова 3.3. Ипотечное жилищное кредитование в республике Башкортостан: настоящее и будущее//Вестник БИСТ (Башкирского института социальных технологий). - 2018. - № 3 (40). - С. 53-56.

3. Добролежа Е.В., Соколов С.В. Что же мешает развиваться отечественному ипотечному жилищному кредитованию в современных условиях? // Инновационные технологии в машиностроении, образовании и экономике. - 2018. - Т. 14. - № 1-2 (7). - С. 125-128.

4. Долматович И.А., Кешенкова Н.В. Ипотечное жилищное кредитование в России: проблемы и решения//Деньги и кредит. - 2017. - № 3. - С. 33-37.

5. Зверев А.В., Мандрон В.В., Мишина М.Ю. Состояние рынка ипотечного кредитования в России на современном этапе//Вопросы региональной экономики. -2018 . - № 3 (36). - С. 117-124.

6. Иванова Д.Г., Шевня В.И. Региональный рынок ипотечного жилищного кредитования: проблемы и тенденции развития//Государственное и муниципальное управление. Ученые записки. - 2018. - № 1. - С. 76-81.

7. Ишханян, М.В., Карпенко, Н.В. Эконометрика: учебное пособие / М.В. Ишханян, Н.В. Карпенко. Часть 1. Парная регрессия. - М.: МГУПС (МИИТ), 2016. 117 c.

8. Караваева Ю.С. Современный рынок ипотечного кредитования и проблемы его развития//Вестник НГИЭИ. - 2018. - № 2 (81). - С. 133-147.

9. Кокин А.С., Осколков И.М., Трофимова Д.С., Ситников Р.Р. Анализ современного состояния рынка ипотечного жилищного кредитования в России//Экономика: вчера, сегодня, завтра. - 2018. - Т. 8. - № 5А. - С. 127-142.

10. Кудрявцева Н.Н., Кудрявцев В.А., Пахомова Ю.В. Оценка структуры розничного кредитного портфеля в ПАО «ВТБ24» и анализ ипотечного кредитования//В сборнике: Организационно-экономические и управленческие аспекты функционирования и развития социально-экономических систем в условиях инновационной экономики. Материалы Всероссийской научно-практической конференции. - 2017. - С. 80-89.

11. Кузьмина М.И. Банковское ипотечное жилищное кредитование: оценка состояния и перспектива развития на примере сбербанка России//Молодой ученый. - 2017. - № 1 (135). - С. 209-212 
12. Морозова Г.В., Филичкина Ю.Ю. Вопросы развития рынка ипотечного кредитования в современных условиях//Финансовая экономика. - 2018. - № 4. C. $222-227$.

13. Нехайчук Д.В., Котелевская Ю.В., Шевчук Л.Е. Региональный разрез формирования кредитной политики современного банковского сектора: Крым и Севастополь//Вестник Алтайской академии экономики и права. - 2019. - № 8-2. - С. 161-167.

14. Новицкая Л.Ю., Кошелева М.В. Некоторые проблемы, связанные с ипотечным кредитованием в Российской Федерации//Экономика. Право. Общество. 2017. - № 3 (11). - C. 57-63.

15. Седых Н.В., Бурховецкая А.А. Анализ и перспективы развития рынка ипотечных жилищных кредитов в России в период кризиса в строительной сфере//В сборнике: современные подходы к трансформации концепций государственного регулирования и управления в социально-экономических системах. Сборник научных трудов 8-й Международной научно-практической конференции. Курск, 2019.- С. 109-114.

16. Сошникова В.С. Проблемы и перспективы развития современного рынка ипотечного кредитования в России и регионе//Молодой ученый. - 2017. № 21-1 (155). - С. 88-92.

17. Анализ развития конкурентной среды на рынке ипотечного кредитования в июле 2020 г. [Электронный ресурс]. - Режим доступа: https://дом.рф/ upload/iblock/ee1/ee19d224c2aa52ee69fe38c508f175ec.pdf (дата обращения 21.08.2020)

18. Дом.рф [Электронный ресурс]. - Режим доступа: https:/дом.рф/analytics/ (дата обращения 20.08.2020)

19. Инфляционные ожидания и потребительские настроения. - 2020. - № 7 (43) [Электронный ресурс]. - Режим доступа: https://cbr.ru/Collection/Collection/ File/29097/Infl_exp_20-07.pdf (дата обращения 21.08.2020)

20. Милюкова А. Аналитики S\&P предсказали удвоение доли плохих долгов россиян из-за кризиса [Электронный ресурс]. - Режим доступа: https://www. forbes.ru/finansy-i-investicii/396763-analitiki-sp-predskazali-udvoenie-doli-plohih-dolgov-rossiyan-iz-za (дата обращения 14.04.2020)

21. Обзор конкурентной среды на рынке ипотечного кредитования по итогам июня 2020 [Электронный ресурс]. - Режим доступа: http://rusipoteka.ru/files/ analytics/ri/2020/konkurentnaya-sreda-na-rynke-ipoteki-iyun-2020.pdf (дата обращения 20.08.2020)

22. Сайт Банка России [Электронный ресурс]. - Режим доступа: https://cbr.ru/Collection/Collection/File/8468/obs_189.pdf (дата 0бращения 20.08.2020)

23. Сайт Федеральной службы государственной статистики [Электронный ресурс]. - Режим доступа: https://rosstat.gov.ru/price (дата 0бращения 21.08.2020)

24. Bank of America предсказал снижение ставки ЦБ России до рекордных 3,5\% [Электронный ресурс]. - Режим доступа: https://www.rbc.ru/finances/15/05/2 020/5ebe47bb9a79477409251732 (дата обращения 21.08.2020)

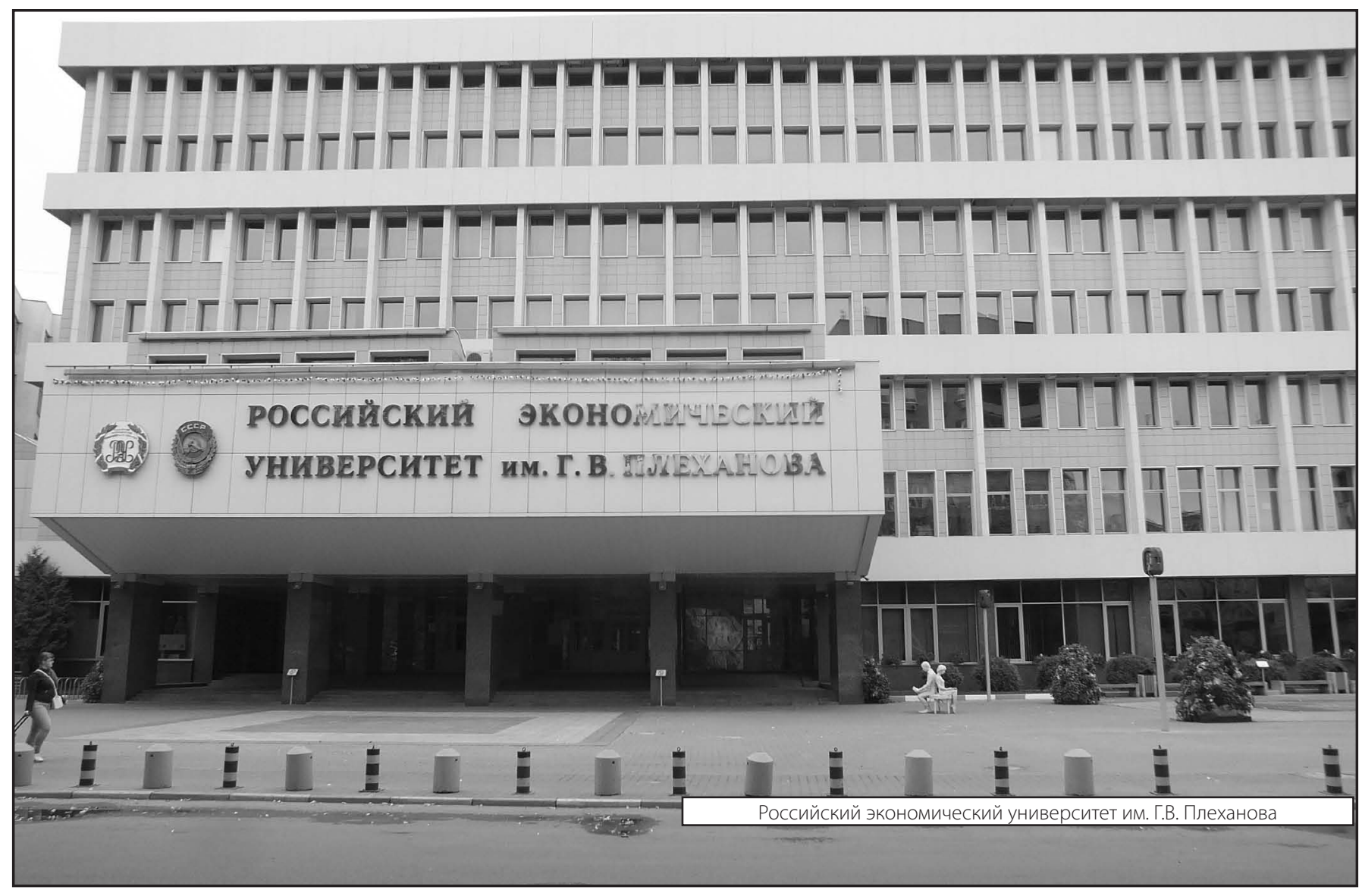

